\title{
A HETEROGENEIDADE DO MERCADO DE TRABALHO E A DESIGUALDADE NA REPRESENTAÇÃO SINDICAL
}

Este ensaio tem por objetivo avaliar a filiação sindical e sua distribuição desigual no mercado de trabalho brasileiro, em uma trajetória de recomposição importante da expressão relativa e absoluta do emprego com carteira de trabalho assinada. Ao longo da década passada, a taxa nacional de sindicalização se manteve praticamente estável na casa dos $25 \%$, sinalizando que a geração de emprego, em termos globais, pode não apresentar uma relação direta com a evolução da representação coletiva dos trabalhadores.

Inicialmente, é preciso reconhecer que o indicador assume muitos significados distintos, posto que a ação sindical pode se orientar para diversas finalidades, muitas vezes não associadas a conquistas voltadas para a melhoria imediata das condições de trabalho para seus representados. Ademais, cabe ressaltar, no que diz respeito à negociação coletiva, que a regulação da extensão de seus resultados tende a influenciar a densidade da sindicalização. $\mathrm{Na}$ experiência brasileira, os resultados do acordo coletivo abrangem os trabalhadores independentemente da sua condição de filiação, não se constituindo em um indutor da sindicalização. Também, é preciso apontar que o financiamento público compulsório dos sindicatos não os induz a ampliarem seus recursos via o aumento do seu grau de sindicalização.

Entretanto, predomina entre os estudiosos do tema das relações de trabalho que a taxa de sindicalização é um indicador relevante da representatividade dos interesses coletivos dos trabalhadores, permitindo compreen- 
der o peso e o papel jogado por estes atores ante a atuação das empresas e do Estado na arena do sistema de relações de trabalho.

A maior parte das análises desenvolvidas sobre o significado atual da taxa de sindicalização brasileira relaciona seu baixo patamar às condições desfavoráveis do mercado de trabalho, produzidas tanto pelo processo de sua constituição como pelos constrangimentos a que ele esteve submetido pela dinâmica da economia brasileira nas últimas duas décadas do século passado. Em relação a este período, aponta-se também que as mudanças tecnológicas articuladas com o processo de racionalização das empresas, que tiveram lugar nos espaços produtivos das mesmas e nas cadeias produtivas, reforçaram a situação de fragilidade da representação sindical.

Considerando as diferenças de ênfase sobre as variáveis causais, o fato é que as análises quase sempre encontram nas formas atuais de uso, da jornada e dos contratos de trabalho os fatores limitantes ao avanço das taxas de sindicalização. Ou seja, as análises, via de regra, pautam a explicação da persistente baixa densidade sindical no Brasil como fenômeno da precariedade do mercado e das relações de trabalho. De outra parte, consideram que a regulação social das relações de trabalho nunca chegou a criar condições para o fortalecimento da organização sindical, tampouco, em razão do caráter segmentado do mercado de trabalho, chegou a se generalizar para o conjunto dos trabalhadores, nas atividades rurais e urbanas (Laranjeira, 2003).

Partindo destas análises, o presente ensaio pretende entender as razões da ocorrência de mudanças limitadas no quadro nacional recente da sindicalização dos trabalhadores, apesar do contexto de forte crescimento do emprego formal e de quedas relativamente importantes dos níveis relativos de desemprego e de informalidade do trabalho, produzidas no mercado de trabalho brasileiro pelo menos desde o ano de 2004. A discussão se centra na análise dos limites que a estrutura fortemente heterogênea de inserção ocupacional por estratos de renda e a regulação parcial do mercado e das relações de trabalho, marcada por forte desigualdade social e econômica, impõem ao avanço dos níveis de associação e representatividade sindical no Brasil.

Para tanto, além desta introdução, na primeira seção do ensaio fizemos uma síntese sobre o caráter estrutural da segmentação do mercado de trabalho brasileiro, o qual engendrou formas de regulação das relações de trabalho que reduziram as possibilidades de organização sindical e de superação das desigualdades das condições de inserção ocupacional e rendimentos. Na segunda seção, demonstramos que o comportamento do mercado de trabalho na última década, ainda que favorável ao emprego formal, não permitiu o avanço da densidade sindical no país em virtude da persistência do movimento de reprodução das desigualdades balizado pelo maior dinamismo do emprego com perfil de baixo rendimento. Em seguida, a partir da análise das características pessoais dos trabalhadores, demonstramos, na terceira seção, 
como a recorrência das contidas taxas de sindicalização na última década guarda forte relação com a natureza dos postos de trabalho, ocupados majoritariamente por segmentos da força de trabalho para os quais a vida sindical é menos representativa. Nas observações finais, tecemos algumas considerações sobre as perspectivas da sindicalização, ao ressaltar a influência dos aspectos ligados ao mercado de trabalho e à estrutura sindical sobre a capacidade de ampliação da organização dos trabalhadores e das negociações coletivas.

\section{A REGULAÇÃo PÚBLICA DO CONTRATO E DAS RELAÇõES DE TRABALHO, ENTRE O REAL E O FORMAL}

O desenvolvimento econômico no Brasil que teve lugar até os anos 1970, apesar de lastreado no aprofundamento do processo de industrialização, teve como resultante a estruturação de um mercado de trabalho socialmente heterogêneo. As oportunidades de trabalho surgidas em meio ao avanço e consolidação de estruturas produtivas modernas conviveram com a multiplicação de postos de trabalho em atividades de baixa produtividade e, com isso, a profusão de formas distintas de inserção ocupacional acabou por moldar padrões de rendimento do trabalho com níveis extremamente desiguais (Oliveira, 2003).

O excesso de oferta de força de trabalho não era, como supunham alguns analistas do tema (Salm \& Eichenberg, 1989), um processo temporário que, mais cedo ou mais tarde, sofreria um refluxo enquanto perdurasse a sucessão de altas taxas de crescimento do produto e, a um só tempo, continuasse a se desenvolver a integração setorial e regional da economia. É verdade que o grande dinamismo que se imprimiu ao emprego assalariado formal absorveu parte importante da força de trabalho com maiores níveis de escolaridade e formação profissional nas empresas. Porém, a maior parte empregou-se em condições muito precárias em virtude da alta disponibilidade de trabalhadores desempregados e ocupados nas atividades informais (Souza, 1980; Cacciamali, 1983; Cacciamali \& Pires, 1996).

Com efeito, o pequeno desenvolvimento do mercado interno de trabalho é sintomático da histórica ausência de regulação pública e sindical sobre o uso da força de trabalho nos locais de trabalho. A liberdade patronal para conduzir a gestão do trabalho nos espaços produtivos enveredou preferencialmente pela ampla prática da rotatividade, ${ }^{1}$ impedindo a sua especialização (que requer o tempo de permanência no emprego necessário para gerar ganhos salariais) por meio do fechamento dos canais internos de mobilidade ocupacional dos trabalhadores, característicos do funcionamento dos mercados de trabalho estruturados (Baltar, 2003). É nesse sentido que se deve explicar, em última instância, a segmentação do trabalho no setor formal. 
Com isso, a segmentação do mercado de trabalho não se revela apenas pelo modo de inserção dos trabalhadores a partir das diferentes posições na ocupação, divididas entre aqueles que possuem e que não possuem os direitos inscritos na legislação trabalhista. As desigualdades de renda atingiram a estrutura ocupacional da atividade econômica como um todo - inclusive no interior do setor formal nucleado nos segmentos modernos da economia -, na qual muitas vezes coexistiram trabalhadores em ocupações passíveis de maior e menor estabilidade no emprego em razão da sobreoferta de força de trabalho e da influência limitada da proteção pública e sindical do mercado de trabalho (Henrique, 1999).

O contrato coletivo de trabalho é, decerto, o mecanismo mais eficiente para reduzir as desigualdades socioeconômicas do mercado de trabalho, especialmente na situação de crescimento econômico. Enquanto a capacidade da política de valorização do piso legal afeta apenas a remuneração de base da economia (divorciada da ascensão dos trabalhadores na estrutura ocupacional), em contrapartida a barganha individual se cinge aos trabalhadores mais qualificados e em posições de comando. As negociações coletivas, dentre as alternativas do salário mínimo e da barganha individual, cumprem este papel de modo mais eficiente, ao conferir maior abrangência dos seus resultados para toda a estrutura salarial compreendida no trabalho assalariado (Dedecca, 2009).

\section{A RECUPERAÇÃO RECENTE DO EMPREGO FORMAL E A EVOLUÇÃo DA SINDICALIZAÇÃo}

A retomada do crescimento econômico na última década, especialmente a partir de 2004, trouxe uma nova dinâmica para o mercado de trabalho determinada pela ponderável geração de empregos formais, que se traduziu em queda expressiva dos indicadores de desemprego aberto e informalidade. $\mathrm{O}$ dinamismo do mercado de trabalho refletiu-se em mudanças da sua estrutura de inserção produtiva a partir da posição na ocupação, ao mostrar que a taxa de crescimento do emprego formal na década foi o dobro da ocupação total, de modo que se pode afirmar que o seu sentido é muito diferente do cenário visto durante os anos 1990, quando as taxas de informalidade aumentaram de modo recorrente no país no contexto de baixo ritmo de crescimento do produto.

O incremento da taxa de ocupação da força de trabalho de $85,6 \%$ para $88,5 \%$, ainda que não possa parecer surpreendente à primeira vista, ocorreu em meio ao crescimento de quase $20 \%$ da população economicamente ativa. Trata-se de fato quase inusitado a estrutura econômica ter suportado crescimento do número de pessoas ocupadas ante o crescimento ainda expressivo 
da População Economicamente Ativa (PEA), imprimindo um ritmo de tal envergadura à geração de empregos, que ao reunir mais de 37 milhões de trabalhadores estatutários e com carteira, acabou por ampliar em cerca de seis pontos percentuais o grau de formalidade do mercado de trabalho na década.

As análises sobre a sindicalização nos países avançados costumam reputar grande importância às mudanças dos níveis de emprego e a reorganização produtiva na definição das trajetórias da sindicalização (Dufour et al., 2010). No mais das vezes, com a existência relativamente incipiente da figura da informalidade no mercado de trabalho naqueles países, ainda mais se considerarmos que o grau de proteção pública do trabalho através do instituto do seguro-desemprego e da regulação sobre os contratos de trabalho é bastante desenvolvido, o movimento sindical atua potencialmente sobre o conjunto da força de trabalho, a despeito das diferentes configurações que assume em cada um destes países.

No Brasil, a estrutura sindical inscrita na Consolidação das Leis do Trabalho de 1943 confere o direito à associação sindical apenas àqueles trabalhadores com vínculo formalizado de emprego, fator estruturalmente limitador da densidade sindical no país, em razão do quadro recorrente e histórico de elevado emprego não registrado no mercado nacional de trabalho. Assim, é razoável presumir que a elevação de $40 \%$ do nível de emprego formalizado fomentaria o incremento da densidade sindical dos trabalhadores. Contudo, percebe-se que entre o início e o final da década a taxa de sindicalização, expressa como a proporção do total de trabalhadores sindicalizados em relação ao emprego formal, reduziu-se, ao passar de $26,4 \%$, em 2001, para $25 \%$, em 2009, não havendo sinalização de reversão da situação que Baglioni (1994) e Rodrigues (1999) classificaram como mercado de trabalho de baixa sindicalização, ${ }^{2}$ indicando, portanto, a existência de outros fatores estruturais na sua determinação, como sugere Cardoso (2006).

Essa questão nos remete à indagação sobre as causas desse fenômeno. É verdade que a série de interpretações que se valiam das mudanças das formas de gestão de trabalho conduzidas nas empresas do segmento privado da economia nos anos 1990 poderia ser utilizada aqui para responder a questão (Cardoso et al., 2001) . Sobretudo as análises que identificavam na paralisia do crescimento dos já pequenos índices de sindicalização as políticas patronais de reorganização produtiva voltadas para a redução do custo do trabalho, expressas no uso do expediente da subcontratação, na flexibilidade da jornada de trabalho e no achatamento dos salários.

De fato, o ritmo de crescimento do emprego formal foi muito lento naquele período e o coeficiente de elasticidade-emprego do produto foi negativo, mas na última década estabeleceu-se progressivamente uma relação cada vez mais positiva (maior que um) no que se refere à resposta do crescimento do emprego em relação às mudanças do produto que, ao se basear na 
utilização crescente da capacidade ociosa e na manutenção da estabilidade dos coeficientes técnicos de produção, determinou uma trajetória ascendente dos indicadores do mercado de trabalho (Dedecca, 2009). Não por acaso, o emprego formal atingiu níveis de crescimento acima do observado para as taxas médias do Produto Interno Bruto (PIB), da PEA e da ocupação total, como pode ser visto na Tabela 1.

No entanto, nota-se que o avanço do emprego formal na última década, apesar de expressivo, não significou a ampliação da taxa nacional de sindicalização. Muito ao contrário, se visto pelo ângulo da densidade sindical, à exceção da Região Norte, as taxas de sindicalização caíram de forma generalizada no país (Tabela 2). Quando se observa a trajetória do número de sindicalizados no país, cujo crescimento correspondeu a $18 \%$ no período e representou a inclusão no mercado de trabalho de mais 2,5 milhões de trabalhadores associados aos sindicatos, constata-se que a proporção desse aumento ficou cerca de seis pontos percentuais abaixo do aumento do emprego do setor privado.

Chama a atenção o fato de que na primeira metade da década, quando a evolução do emprego sindicalizado foi maior que o emprego total, o crescimento dos níveis de sindicalização foi mais intenso no Norte e no Centro-Oeste, regiões que sempre se caracterizaram pelas baixas taxas de sindicalização. No período 2005-2009, no qual o emprego cresceu mais de $20 \%$, houve um recuo do número absoluto de sindicalizados na Região Sul, que sempre se destacou pela elevada densidade sindical, e por outro lado, um aumento expressivo da sindicalização na Região Nordeste.

O aumento da sindicalização no Norte e no Centro-Oeste, onde o contingente de empregados com vínculo formal de emprego é muito inferior às demais regiões em termos absolutos e relativos, mostra como o seu crescimento notável dos níveis de sindicalização não foi capaz de conter a queda da taxa nacional de sindicalização. Mais do que isso, trata-se de regiões onde as atividades econômicas modernas com mercados de trabalho estruturados são relativamente pouco desenvolvidas e a vida sindical é historicamente apresenta menor expressão, uma vez que ainda é pequena a presença dos segmentos de atividade ligados à indústria.

Para se ter maior clareza sobre isso, quando se observa o ritmo de sindicalização no país por setor econômico, percebe-se a superioridade do número de empregados associados aos sindicatos nas atividades agrícolas, nos segmentos de alojamento e alimentação e na indústria de construção, setores que experimentaram um ligeiro crescimento das taxas de sindicalização. Assim, os níveis de sindicalização avançaram predominantemente para os perfis de ocupação presentes nos segmentos de atividade com menor participação no emprego, menor produtividade e baixos níveis absolutos e relativos de salário, de modo que a recuperação econômica não significou a subida relevante da renda do trabalho. 


\begin{tabular}{|c|c|c|c|c|c|c|}
\hline Fatores & 2001 & 2003 & 2005 & 2007 & 2009 & $\begin{array}{l}\text { Variação } \\
\text { Acumulada } \\
\text { 2001-2009 }\end{array}$ \\
\hline PIB Real (1) & 2.400 .959 & 2.534 .574 & 2.764 .015 & 3.048 .418 & 3.185 .125 & 30,5 \\
\hline PIB Real Per Capita (2) & 14,04 & 14,18 & 15,07 & 16,25 & 16,63 & 18,4 \\
\hline PEA & 75.772 .197 & 77.225 .289 & 82.440 .002 & 87.801 .924 & 90.408 .042 & 19,3 \\
\hline Ocupação Remunerada & 64.882 .103 & 68.508 .491 & 73.559 .107 & 76.805 .861 & 80.051 .583 & 23,4 \\
\hline $\begin{array}{l}\text { Sindicalizados: } \\
\text { Setor Privado }\end{array}$ & 26.455 .725 & 28.354 .561 & 31.352 .841 & 34.560 .303 & 37.250 .266 & 40,8 \\
\hline $\begin{array}{l}\text { Sindicalizados: } \\
\text { Setor Público }\end{array}$ & 5.735 .071 & 6.481 .105 & 7.402 .807 & 7.242 .581 & 7.748 .255 & 35,1 \\
\hline $\begin{array}{l}\text { Sindicalizados: } \\
\text { Total }\end{array}$ & 1.797 .090 & 1.908 .891 & 2.076 .863 & 2.263 .165 & 2.419 .940 & 34,7 \\
\hline Emprego Formal & 7.532.161 & 8.389 .996 & 9.479 .670 & 9.505 .746 & 10.168 .195 & 35,0 \\
\hline
\end{tabular}

Tabela 1: Indicadores de Evolução do Produto Interno Bruto, de Participação Econômica e da Ocupação. Brasil, 2001/2009.

Fonte: Pesquisa Nacional por Amostra de Domicílios, PNAD/IBGE, Microdados; Ipeadata. Elaboração própria.

(1) Em milhões de Reais de 2009.

(2) Em mil Reais de 2009.

\begin{tabular}{l|r|r|r|r|r|r|r} 
& \multicolumn{4}{|c|}{ Taxa de Sindicalização } & \multicolumn{2}{c}{$\begin{array}{c}\text { Variação Acumulada do } \\
\text { Emprego 2001-2009 }\end{array}$} \\
\cline { 2 - 9 } & 2001 & 2003 & 2005 & 2007 & 2009 & Sindicalizado & Total \\
\hline Norte & 17,2 & 22,2 & 25,9 & 18,4 & 18,5 & 78,0 & 66,0 \\
\hline Nordeste & 27,1 & 27,9 & 28,5 & 26,8 & 26,9 & 52,3 & 53,6 \\
\hline Sudeste & 25,9 & 27,9 & 28,0 & 25,0 & 25,4 & 35,3 & 38,0 \\
\hline Sul & 31,2 & 30,7 & 31,8 & 28,4 & 25,8 & 13,3 & 36,9 \\
\hline Centro-Oeste & 20,6 & 23,3 & 23,8 & 19,6 & 20,3 & 55,4 & 57,4 \\
\hline Total & 26,4 & 27,9 & 28,4 & 25,2 & 25,0 & 35,1 & 42,6
\end{tabular}

Tabela 2: Taxa de Sindicalização do Emprego Formal do Setor Privado segundo Regiões Geográficas. Brasil, 2001/2009 Fonte: Pesquisa Nacional por Amostra de Domicílios, PNAD/IBGE. Microdados. Elaboração própria. 
Ao contrário do que se observou para o movimento do emprego, a elevação do rendimento médio real foi menos acentuada, não permitindo recuperar o patamar prevalecente durante o Plano Real. A repercussão da contida evolução do valor dos salários só não foi sentida entre os trabalhadores da base do mercado de trabalho, posto que houve maior crescimento do rendimento médio para esse estrato da mão de obra e, mais do que isso, engrossou-se a parcela dos trabalhadores com rendimentos entre um e dois salários mínimos na estrutura salarial.

A explicação para a ampliação do grau de concentração dos rendimentos em torno do salário mínimo reside na própria dinâmica e no perfil de renda dos empregos criados ao longo da década que, por sinal, testemunharam a elevação das taxas de sindicalização. É verdade que o crescimento do emprego formal e sindicalizado, mais intenso no segmento privado da economia, mostrou um desempenho mais robusto do que o crescimento da ocupação total e no setor público (Tabela 1). Contudo, ao se decompor a análise do trabalho no setor privado por classes de salário mínimo, observa-se que o ritmo de criação de empregos sindicalizados com variação percentual acima do emprego total atingiu apenas os trabalhadores com remunerações próximas (e influenciadas pelo reajuste) do piso salarial legal.

Aliás, não se poderia esperar outra coisa do comportamento da taxa nacional de sindicalização da força de trabalho na última década, senão o retrocesso desse indicador, quando se verifica que a participação do emprego sindicalizado recuou em proporção semelhante ao do conjunto do emprego formal para os trabalhadores com remunerações superiores a dois salários mínimos. Em suma, "a dinâmica do mercado de trabalho não tem favorecido o emprego com filiação à entidade de representação coletiva, fato que tende a conter seja uma tendência de elevação da taxa de sindicalização, seja a influência das negociações coletivas na evolução do salário real" (Dedecca, 2009: 145).

Não por acaso, foi justamente no segmento dos trabalhadores sindicalizados do setor privado dos estratos inferiores de renda (até os $40 \%$ mais pobres) que o crescimento do emprego sindicalizado mais avançou entre 2001 e 2009, inclusive em proporções superiores ao crescimento do emprego formal como um todo. À primeira vista, tal movimento revelaria o dinamismo, salutar, da filiação sindical entre os trabalhadores de baixo na estrutura de distribuição dos rendimentos do trabalho. Contudo, ao se analisar este aspecto a partir do contexto mais amplo, verifica-se que a base de número de sindicalizados sobre a qual ocorreu tal crescimento é muito limitada em relação ao emprego como um todo, de modo que sua evolução não modifica substantivamente o quadro de baixa sindicalização no país.

A evolução dos rendimentos do trabalho foi mais expressiva para os estratos inferiores e médios da estrutura ocupacional, independentemente 


\begin{tabular}{|c|c|c|c|c|c|c|c|}
\hline & & Norte & Nordeste & Sudeste & Sul & $\begin{array}{l}\text { Centro- } \\
\text { Oeste }\end{array}$ & Brasil \\
\hline \multirow{3}{*}{2001} & Empregados & 749.927 & 3.020 .073 & 11.717 .286 & 3.940 .469 & 1.382 .923 & 20.810 .678 \\
\hline & Sindicalizados & 120.394 & 832.997 & 2.988 .541 & 1.218 .587 & 268.913 & 5.429 .432 \\
\hline & Não-sindicalizados & 629.533 & 2.187 .076 & 8.727 .334 & 2.721 .882 & 1.114 .010 & 15.379 .835 \\
\hline \multirow{3}{*}{2003} & Empregados & 750.069 & 2.903 .649 & 10.438 .395 & 3.797 .838 & 1.317 .234 & 19.207 .185 \\
\hline & Sindicalizados & 159.356 & 804.749 & 2.823 .725 & 1.144 .480 & 273.805 & 5.206 .115 \\
\hline & Não-sindicalizados & 590.713 & 2.098 .900 & 7.614 .670 & 2.653 .358 & 1.043 .429 & 14.001 .070 \\
\hline \multirow{3}{*}{2005} & Empregados & 924.227 & 3.235 .046 & 11.730 .642 & 4.255 .590 & 1.554 .585 & 21.700 .090 \\
\hline & Sindicalizados & 223.553 & 917.652 & 3.275 .675 & 1.349 .665 & 348.441 & 6.114 .986 \\
\hline & Não-sindicalizados & 700.674 & 2.317 .394 & 8.454 .967 & 2.905 .925 & 1.206 .144 & 15.585 .104 \\
\hline \multirow{3}{*}{2009} & Empregados & 1.156 .428 & 4.187 .163 & 14.028 .599 & 4.922 .099 & 1.915 .613 & 26.209 .902 \\
\hline & Sindicalizados & 202.855 & 1.089 .499 & 3.526 .129 & 1.267 .093 & 354.623 & 6.440 .199 \\
\hline & Não-sindicalizados & 953.573 & 3.067 .664 & 10.502 .470 & 3.655 .006 & 1.560 .990 & 19.769.703 \\
\hline \multirow{3}{*}{ Var.\%2009-01 } & Empregados & 25,12 & 29,43 & 19,59 & 15,66 & 23,22 & 20,78 \\
\hline & Sindicalizados & $(9,26)$ & 18,73 & 7,65 & $(6,12)$ & 1,77 & 5,32 \\
\hline & Não-sindicalizados & 36,09 & 33,67 & 24,22 & 25,78 & 29,42 & 26,85 \\
\hline \multirow{3}{*}{ Var.\%2009-01 } & Empregados & 54,21 & 38,64 & 19,73 & 24,91 & 38,52 & 25,94 \\
\hline & Sindicalizados & 68,49 & 30,79 & 17,99 & 3,98 & 31,87 & 18,62 \\
\hline & Não-sindicalizados & 51,47 & 41,63 & 20,34 & 34,28 & 40,12 & 28,54 \\
\hline \multirow{3}{*}{ Var.\%2009-01 } & Empregados & 54,21 & 38,64 & 19,73 & 24,91 & 38,52 & 25,94 \\
\hline & Sindicalizados & 68,49 & 30,79 & 17,99 & 3,98 & 31,87 & $18, .62$ \\
\hline & Não-sindicalizados & 51,47 & 41,63 & 20,34 & 34,28 & 40,12 & 28,54 \\
\hline
\end{tabular}

Tabela 3: Número e Variação Relativa de Empregados Sindicalizados, Não-Sindicalizados e Total. Brasil e grandes regiões, 2001/2009

Fonte: Pesquisa Nacional por Amostra de Domicílios, PNAD/IBGE, Microdados. Elaboração própria. 
da categoria profissional, devido à valorização do salário mínimo. Tal movimento foi reforçado pela geração mais expressiva de empregos nestes estratos, que se apresentou de modo generalizado nas diversas regiões geográficas e setores de atividade econômica, particularmente naqueles com níveis mais baixos de produtividade. No entanto, sem desconsiderar o fato de que, ao reunir um estoque robusto de emprego com participação absoluta e relativamente grande no plano nacional (Tabela 2), as regiões mais industrializadas do país também jogaram um papel decisivo na definição da trajetória cadente da taxa de sindicalização no curso da última década, como ficou patente no caso da Região Sul.

Com efeito, parcela importante das vagas de trabalho abertas no setor formal durante o período, independente do grau de desenvolvimento econômico regional, tiveram lugar principalmente em segmentos produtivos menos modernos da economia e, consequentemente, com baixos níveis de rendimento. Não por acaso os postos de trabalho com perfil ocupacional de pouca qualificação e o emprego nas pequenas e médias empresas tiveram maior peso no crescimento dos níveis de ocupação formal que, por conta dessas características, não passam incólumes às injunções típicas da precariedade dos mercados de trabalho não-estruturados que caracteriza o regime de trabalho no Brasil, expressas nas altas taxas de rotatividade e na baixa efetividade das negociações coletivas.

Chega-se à conclusão que a taxa nacional de sindicalização no Brasil recuou durante a última década porque a maior parte dos postos de trabalho formais criados no país corresponde aos níveis mais inferiores de remuneração da estrutura ocupacional que, por sua vez, exibem as menores taxas de sindicalização. Não se quer dizer com isso que os índices de dispersão e desigualdades salariais não tenham diminuído (esta questão não é objeto da presente análise), mas apenas mostrar que a geração de empregos de trabalhadores sindicalizados esteve muito concentrada nos estratos de renda cuja participação relativa do emprego é pequena no conjunto do mercado formal de trabalho.

Vejamos, a partir da próxima seção, como a análise das características pessoais dos trabalhadores e da natureza das ocupações completa o quadro de explicação dos limites da sindicalização no Brasil.

\section{AS CONDIÇÕES PESSOAIS DE INSERÇÃO DOS TRABALHADORES}

Quando se observa a condição de inserção dos trabalhadores associados aos sindicatos segundo sexo no mercado formal de trabalho, fica evidente que a maior parte do emprego sindicalizado feminino criado durante a última década, tal como se testemunhou para o setor privado como um todo, cresceu 


\begin{tabular}{|c|c|c|c|c|c|c|c|}
\hline & \multicolumn{5}{|c|}{ Taxa de Sindicalização } & \multicolumn{2}{|c|}{$\begin{array}{l}\text { Variação Acumulada } \\
\text { do Emprego 2001-2009 }\end{array}$} \\
\hline & 2001 & 2003 & 2005 & 2007 & 2009 & Sindicalizado & Total \\
\hline Agrícola & 22,4 & 22,8 & 25,4 & 24,1 & 24,7 & 41,1 & 27,8 \\
\hline Indústria de construção & 19,1 & 21,5 & 22,5 & 19,0 & 20,7 & 91,4 & 76,6 \\
\hline Indústria de transformação & 30,0 & 32,2 & 33,8 & 29,6 & 28,9 & 24,7 & 29,5 \\
\hline Outras atividades industriais & 43,4 & 42,4 & 42,3 & 37,2 & 39,8 & 30,9 & 43,0 \\
\hline Comércio e reparação & 19,3 & 20,1 & 21,4 & 18,5 & 19,4 & 62,9 & 62,2 \\
\hline Alojamento e alimentação & 15,8 & 18,6 & 20,7 & 17,2 & 16,7 & 61,2 & 52,7 \\
\hline $\begin{array}{l}\text { Transporte, armazenagem e } \\
\text { comunicação }\end{array}$ & 37,6 & 38,2 & 37,9 & 33,0 & 32,2 & 16,5 & 36,0 \\
\hline $\begin{array}{l}\text { Educação, saúde e } \\
\text { serviços sociais }\end{array}$ & 28,3 & 29,0 & 29,0 & 26,4 & 26,6 & 24,2 & 32,3 \\
\hline $\begin{array}{l}\text { Outros serviços coletivos, } \\
\text { sociais e pessoais }\end{array}$ & 22,5 & 24,3 & 22,8 & 21,7 & 21,0 & 40,3 & 50,7 \\
\hline Total & 26,4 & 27,9 & 28,4 & 25,2 & 25,0 & 35,1 & 42,6 \\
\hline
\end{tabular}

Tabela 4: Taxas de Sindicalização do Emprego Formal do Setor Privado segundo Setor de Atividade Econômica. Brasil, 2001/2009

Fonte: Pesquisa Nacional por Amostra de Domicílios, PNAD/IBGE. Microdados. Elaboração própria.

\begin{tabular}{|c|c|c|c|c|c|c|}
\hline \multirow[b]{3}{*}{ Em Classes de Salário Mínimo } & \multicolumn{4}{|c|}{ Distribuição Relativa } & \multirow{2}{*}{\multicolumn{2}{|c|}{$\begin{array}{l}\text { Variação Acumulada } \\
\text { 2001-2009 }\end{array}$}} \\
\hline & \multicolumn{2}{|c|}{ Sindicalizado } & \multicolumn{2}{|l|}{ Total } & & \\
\hline & 2001 & 2009 & 2001 & 2009 & Sindicalizado & Total \\
\hline Menos de 1 & 0,9 & 0,4 & 1,5 & 0,6 & $-46,1$ & $-39,9$ \\
\hline De 1 a menos de 2 & 29,6 & 51,7 & 42,2 & 64,3 & 136,0 & 117,2 \\
\hline De 2 a menos de 3 & 22,8 & 20,2 & 24,0 & 16,7 & 19,4 & $-0,9$ \\
\hline De 3 a menos de 5 & 21,8 & 15,3 & 17,0 & 11,2 & $-5,2$ & $-6,2$ \\
\hline De 5 a menos de 7 & 9,8 & 5,6 & 6,8 & 3,5 & $-23,2$ & $-26,3$ \\
\hline De 7 a menos de 10 & 5,0 & 3,0 & 3,1 & 1,7 & $-19,2$ & $-21,4$ \\
\hline De 10 ou mais & 10,0 & 3,9 & 5,5 & 2,1 & $-47,4$ & $-46,0$ \\
\hline Total & 100,0 & 100,0 & 100,0 & 100,0 & 35,1 & 42,6 \\
\hline
\end{tabular}

Tabela 5: Evolução do Emprego Formal do Setor Privado segundo Classes de Salário Mínimo. Brasil, 2001/2009

Fonte: Pesquisa Nacional por Amostra de Domicílios, PNAD/IBGE. Microdados. Elaboração própria. 
de forma concentrada para as ocupações situadas nos estratos inferiores da estrutura de rendimento. Todavia, apesar do avanço rápido dos níveis de sindicalização, o contingente da força de trabalho das mulheres mais pobres respondeu por uma participação relativamente pequena no estoque total do emprego feminino e, por isso mesmo, incapaz de influenciar positivamente a taxa geral de sindicalização, que acabou recuando no período.

A evolução dos níveis de emprego sindicalizado no terço mais pobre da estrutura de salários desse segmento da força de trabalho, cujo aumento correspondeu a cerca de 15 pontos percentuais no período 2001-2009, imprimiu ritmo muito superior ao crescimento relativo da participação média do conjunto das mulheres sindicalizadas (1,4 p.p.) e do estoque total do emprego feminino (1,8 p.p.) no emprego total (Tabela 6). Com isso, as diferenças entre homens e mulheres no que se refere à representação sindical reiteram o nosso argumento segundo o qual a desigualdade no mercado de trabalho, agora vista especificamente sob o ângulo das condições de gênero, explica a preservação da baixa densidade sindical no país.

O aumento da parcela de mulheres sindicalizadas nos níveis de menor rendimento da estrutura salarial é resultante do perfil do emprego criado ao longo da década, cuja geração de postos de trabalho teve lugar principalmente nas atividades econômicas de agricultura, indústria extrativa e construção, setores nos quais predominam os salários de base do mercado de trabalho e maior instabilidade do vínculo de emprego. Ademais, ao se caracterizarem como setores com remunerações do trabalho inferiores em virtude da sua baixa produtividade, a participação da mão de obra no total do emprego formal, em geral, e do emprego feminino, em particular, é bastante reduzida. Portanto, não obstante o crescimento dos níveis de sindicalização, a própria condição de insegurança do emprego e da renda que atinge principalmente as trabalhadoras mais pobres impõe limites estruturais ao avanço da taxa de sindicalização.

Mais do que isso, ao observar novamente as informações da Tabela 6, nota-se com clareza que a participação relativa do emprego feminino sindicalizado no emprego total diminui à medida que aumentam os níveis de rendimento, movimento este que se acirra entre o início e o fim da última década com a presença cada vez maior de mulheres percebendo remunerações com valores ao redor do salário mínimo. Trata-se de dado que revela como a evolução do emprego feminino sindicalizado e não-sindicalizado, cujo maior dinamismo teve lugar nos mercados de trabalho pouco estruturados, não foi capaz de alterar a tendência histórica (subjacente à segmentação presente no setor formal brasileiro) de favorecer a criação de vagas para as ocupações menos protegidas pela negociação coletiva e, portanto, mais vulneráveis às flutuações econômicas e às injunções da política patronal.

Do mesmo modo, não se pode presumir, tampouco afirmar, que a ampliação do emprego formal significou a inserção maciça de jovens no merca- 


\begin{tabular}{|c|c|c|c|c|c|c|c|c|c|c|c|c|}
\hline & \multirow{2}{*}{\multicolumn{4}{|c|}{$\begin{array}{l}\text { Participação do Emprego } \\
\text { Feminino no Emprego Total }\end{array}$}} & \multicolumn{8}{|c|}{ Idade Média } \\
\hline & & & & & \multicolumn{4}{|c|}{ Sindicalizados } & \multicolumn{4}{|l|}{ Total } \\
\hline & \multicolumn{2}{|c|}{ Sindicalizados } & \multicolumn{2}{|l|}{ Total } & \multicolumn{2}{|c|}{ Homens } & \multicolumn{2}{|c|}{ Mulheres } & \multicolumn{2}{|c|}{ Homens } & \multicolumn{2}{|c|}{ Mulheres } \\
\hline & 2001 & 2009 & 2001 & 2009 & 2001 & 2009 & 2001 & 2009 & 2001 & 2009 & 2001 & 2009 \\
\hline Decil 1 & 45,1 & 45,4 & 43,3 & 44,7 & 34 & 35 & 33 & 35 & 31 & 32 & 32 & 33 \\
\hline Decil 2 & 46,3 & 53,8 & 44,6 & 51,2 & 32 & 34 & 32 & 32 & 31 & 32 & 31 & 31 \\
\hline Decil 3 & 42,8 & 49,5 & 42,4 & 49,3 & 32 & 34 & 32 & 33 & 31 & 32 & 31 & 32 \\
\hline Decil 4 & 40,3 & 42,1 & 40,3 & 42,8 & 33 & 34 & 33 & 34 & 31 & 33 & 31 & 32 \\
\hline Decil 5 & 34,6 & 37,2 & 34,2 & 36,7 & 34 & 36 & 33 & 34 & 33 & 34 & 31 & 32 \\
\hline Decil 6 & 32,5 & 32,4 & 31,8 & 31,8 & 34 & 36 & 33 & 34 & 33 & 35 & 31 & 33 \\
\hline Decil 7 & 26,1 & 26,9 & 26,6 & 28,2 & 35 & 36 & 33 & 35 & 35 & 35 & 32 & 34 \\
\hline Decil 8 & 23,9 & 22,2 & 26,2 & 24,1 & 36 & 38 & 35 & 36 & 36 & 37 & 33 & 35 \\
\hline Decil 9 & 29,0 & 27,6 & 29,3 & 28,3 & 38 & 38 & 35 & 35 & 37 & 37 & 34 & 35 \\
\hline Decil 10 & 27,1 & 28,5 & 26,6 & 28,6 & 40 & 41 & 39 & 40 & 39 & 40 & 37 & 38 \\
\hline Total & 32,4 & 33,8 & 34,5 & 36,3 & 35 & 36 & 34 & 35 & 34 & 35 & 32 & 33 \\
\hline
\end{tabular}

Tabela 6: Participação da Mulher e Idade Média do Emprego Formal do Setor Privado segundo Estratos de Rendimento do Trabalho Principal. Brasil, 2001/2009

Fonte: Pesquisa Nacional por Amostra de Domicílios, PNAD/IBGE, Microdados. Elaboração própria. 
do de trabalho, o que supostamente explicaria o aumento da participação dos trabalhadores nos decis inferiores de rendimento da estrutura de distribuição salarial e, de outra parte, justificaria a lenta resposta da taxa de sindicalização aos impulsos do crescimento do emprego. Os dados estampados na Tabela 6 mostram que, bem ao contrário disso, não houve mudanças significativas do perfil etário dos trabalhadores sindicalizados entre o início e o fim da última década, sejam eles homens ou mulheres, com maiores ou menores níveis de rendimento, ou associados ou não a alguma organização de representação sindical.

Ao olhar ainda mais de perto os mesmos dados, a hipótese da inserção juvenil no mercado de trabalho como explicação para a queda da taxa de sindicalização na década não encontra fundamento empírico, visto que, em primeiro lugar, a idade média do total da força de trabalho empregada e sindicalizada se situa de forma generalizada na faixa etária entre 30 e 40 anos, o que por si só já desautoriza a hipótese da possível influência da entrada maciça de trabalhadores jovens sobre a trajetória da densidade sindical no país. Em segundo lugar, os trabalhadores sindicalizados pertencentes aos estratos inferiores e superiores da estrutura salarial guardam poucas diferenças entre si em termos das suas características etárias, de modo a se poder depreender disso a existência de sinais concretos apontando no sentido estrutural da reprodução da segmentação do mercado de trabalho em meio ao crescimento do emprego.

A comparação entre mulheres e homens empregados no mercado formal de trabalho mostra que, a despeito da queda relativamente pronunciada do número de trabalhadores com pouca escolaridade durante a década, as primeiras se encontram em posição mais favorável, sob este aspecto, em toda a estrutura salarial, como se pode constatar pela menor participação do número de mulheres sindicalizadas e não-sindicalizadas sem o ensino fundamental completo no total do emprego formal (Tabela 7). No entanto, esta situação aparentemente favorável ao aumento do grau de representação sindical, considerando o fato de que o maior nível de escolaridade denotaria maior capacidade de percepção da eficácia da representação coletiva de interesses nos processos de negociação, não se traduziu no aumento da taxa de sindicalização em virtude da natureza precária da maior parte dos postos de trabalho criados.

Se considerarmos a escolaridade enquanto variável analítica que denota aproximação com o nível de qualificação profissional da mão de obra, percebe-se que a maior qualificação das mulheres em relação aos homens não foi uma característica decisiva para modificar a sua situação desfavorável em termos de representação sindical. Isso fica patente quando se observa que, independente da condição de inserção no trabalho segundo sexo, as maiores taxas de participação do número de empregados pouco qualificados 


\begin{tabular}{|c|c|c|c|c|c|c|c|c|}
\hline & \multicolumn{8}{|c|}{ Participação do Emprego sem o Fundamental Completo no Emprego Total } \\
\hline & \multicolumn{4}{|c|}{ Sindicalizados } & \multicolumn{4}{|l|}{ Total } \\
\hline & \multicolumn{2}{|l|}{ Homens } & \multicolumn{2}{|l|}{ Mulheres } & \multicolumn{2}{|l|}{ Homens } & \multicolumn{2}{|l|}{ Mulheres } \\
\hline & 2001 & 2009 & 2001 & 2009 & 2001 & 2009 & 2001 & 2009 \\
\hline Decil 1 & 47,6 & 55,9 & 44,8 & 31,1 & 67,9 & 49,7 & 44,6 & 27,5 \\
\hline Decil 2 & 62,7 & 43,0 & 41,5 & 17,5 & 62,9 & 41,6 & 40,3 & 20,3 \\
\hline Decil 3 & 59,4 & 41,2 & 40,2 & 22,3 & 59,0 & 40,3 & 33,9 & 20,4 \\
\hline Decil 4 & 53,3 & 36,5 & 32,7 & 21,7 & 55,3 & 36,7 & 28,3 & 21,0 \\
\hline Decil 5 & 49,8 & 34,3 & 25,8 & 15,5 & 52,9 & 35,4 & 24,2 & 22,4 \\
\hline Decil 6 & 46,3 & 32,6 & 16,6 & 11,9 & 49,7 & 34,3 & 16,8 & 23,4 \\
\hline Decil 7 & 43,8 & 26,0 & 12,6 & 5,8 & 44,3 & 28,8 & 11,2 & 20,7 \\
\hline Decil 8 & 38,2 & 24,3 & 5,2 & 1,1 & 39,9 & 25,0 & 9,0 & 19,0 \\
\hline Decil 9 & 26,9 & 17,3 & 1,8 & 1,1 & 27,4 & 18,7 & 31 & 13,4 \\
\hline Decil 10 & 7,1 & 6,0 & 0,5 & 0,6 & 8,6 & 6,8 & 1,2 & 4,8 \\
\hline Total & 38,2 & 26,2 & 20,1 & 12,8 & 54,2 & 30,7 & 24,1 & 19,6 \\
\hline
\end{tabular}

Tabela 7: Participação do Emprego sem o Fundamental Completo no Emprego Total do Setor Privado segundo Estratos de Rendimento do Trabalho Principal. Brasil, 2001/2009

Fonte: Pesquisa Nacional por Amostra de Domicílios, PNAD/IBGE, Microdados. Elaboração própria. 
encontram-se (apesar da sua expressiva redução durante a década) nos estratos inferiores de rendimento dos trabalhadores sindicalizados, onde normalmente preponderam as ocupações com pouco tempo de duração do vínculo de emprego e, sendo assim, pode-se dizer que a qualificação não se constitui na característica determinante do tipo de inserção ocupacional.

Essa constatação reforça a ideia de que a sindicalização não apresenta uma correlação direta com o grau de escolaridade dos trabalhadores empregados nos mercados de trabalho pouco estruturados, tanto entre homens quanto entre mulheres, algo já consagrado há muito tempo na literatura sobre a segmentação do mercado de trabalho. É bem verdade, como fica patente pelo exame dos dados da Tabela 7, que as taxas de sindicalização avançam com os maiores requerimentos de qualificação da mão de obra. Contudo, a análise da dinâmica do emprego desenvolvida aqui mostra que a qualificação não é, de fato, um ativo decisivo para o preenchimento da maioria dos postos de trabalho criados no país, tendo em vista a natureza e o perfil precário da maior parte do emprego demandado no mercado de trabalho durante a última década.

\section{OBSERVAÇÕES FINAIS}

Este ensaio teve o objetivo de apresentar uma reflexão sobre a evolução da taxa de sindicalização no setor privado ao longo da década passada a partir das informações disponíveis na Pesquisa Nacional por Amostra de Domicílios (PNAD). A relevância da análise decorre do fato de a economia brasileira ter rompido o estado de estagnação que a marcou durante as décadas de 1980 e 1990, tendo restabelecido a perspectiva de crescimento de mais longo prazo e uma ponderável capacidade de geração de empregos formais. A partir de 2004, tanto o desemprego como a informalidade trilharam uma trajetória descendente, resultado da recomposição do mercado de trabalho formal. Mesmo que o processo tenha apresentado limitações, pois 1 de cada 3 empregos ainda continuava sem registro em carteira em 2009, é inegável que ele produziu uma alteração das condições de contratação de força de trabalho, reduzindo as desvantagens dos trabalhadores na busca e na manutenção de seu emprego.

Em face das alterações positivas das condições gerais do mercado de trabalho brasileiro, é razoável e importante colocar a pergunta se o movimento foi acompanhado da recomposição da densidade da representação sindical. A resposta à questão deve reconhecer que a difusão dos resultados da negociação coletiva para o conjunto das categorias profissionais envolvidas e a existência de um financiamento público compulsório para os sindicatos, aliadas à regulação parcial dos contratos e das relações de trabalho e 
da ampla informalidade, são aspectos institucionais que tendem a não estimular uma maior sindicalização no Brasil. Mesmo assim, seria de se esperar que melhores condições de emprego estimulassem o interesse dos trabalhadores para uma relação mais formal com os sindicatos e com a ação coletiva, em geral expressa por uma maior filiação associativa.

Os resultados da análise não sinalizam a ocorrência de um movimento ascendente da densidade sindical na década passada, apesar de a criação de empregos de menor remuneração ter sido acompanhada por uma evolução ponderável da parcela sindicalizada. Ao longo do período, observa-se uma pequena retração da taxa de sindicalização, sugerindo um quadro de estabilidade durante o movimento de recomposição do mercado de trabalho. É possível que o curto período de vigência dos novos vínculos empregatícios, em um contexto marcado por elevada rotatividade, seja também um elemento de restrição à elevação da densidade sindical. A continuidade do crescimento com geração de empregos, caso seja confirmada, poderá se traduzir em uma maior estabilidade dos vínculos empregatícios de modo a contribuir para a elevação da taxa de sindicalização. É lógico, entretanto, que a consecução deste resultado dependerá de iniciativas dos sindicatos de maior convencimento junto à sua base de representação.

Mesmo que esta expectativa mais positiva venha a se confirmar, os resultados da década passada mostram que uma alteração expressiva do quadro de sindicalização no mercado formal de trabalho deverá enfrentar um quadro estrutural e histórico desfavorável em termos de organização coletiva do trabalho no país. As implicações adversas da atual regulação pública dos contratos e das relações de trabalho sobre a organização e a negociação coletivas se constituem em entraves importantes para o avanço da sindicalização, o qual deve ser considerado como instrumento fundamental para uma melhor estruturação e proteção social do mercado de trabalho.

Recebido em 08/02/12|Aprovado em 16/10/12 
Carlos Henrique Menezes Garcia é doutor em Desenvolvimento Econômico pela Universidade Estadual de Campinas (UNICAMP), professor e pesquisador do Centro Estadual de Educação Tecnológica Paula Souza. Atua em pesquisas nas áreas de economia social e do trabalho, sociologia do trabalho e economia do conhecimento. Tem se dedicado aos seguintes temas: reestruturação produtiva, mercado de trabalho, sindicalismo, políticas sociais e qualificação profissional.

Claudio Salvadori Dedecca é professor titular do Instituto de Economia da Universidade Estadual de Campinas (UNICAMP) e pesquisador do Conselho Nacional de Desenvolvimento Científico e Tecnológico (CNPq). Dedica-se ao estudo da economia social e do trabalho, do crescimento, flutuações e planejamento econômico, com ênfase nas temáticas da regulação social, políticas sociais, mercado de trabalho, relações de trabalho e recursos humanos em ciência e tecnologia. 


\section{NOTAS}

1 Com as novas instituições de regulação do mercado e relações de trabalho implementadas pelo governo militar, agravou-se ainda mais o quadro de dispersão dos salários nas empresas criado pela sobreoferta de força de trabalho. Ao se promover o controle estatal dos salários dos setores público e privado em compasso com a instituição do Fundo de Garantia por Tempo de Serviço (FGTS), além de passarem a ter o direito de arbitrar livremente sobre o uso e a remuneração do trabalho, as empresas ganharam autonomia patronal quanto à sua capacidade de contratação e demissão dos trabalhadores.

2 A medida de taxa de sindicalização da força de trabalho utilizada pelos autores se classifica em baixa sindicalização (menos de $30 \%$ ), média sindicalização (entre $30 \%$ e $50 \%$ ) e elevada sindicalização (mais de 50\%).

\section{REFERÊNCIAS BIBLIOGRÁFICAS}

Baglioni, Guido. (1994). As relações industriais na Europa nos anos 1980. In: Oliveira, Carlos Alonso Barbosa et al. (orgs.). O mundo do trabalho: crise e mudança no final do século. São Paulo: Scritta, p. 49-106.

Baltar, Paulo Eduardo. (2003). Salários e preços: esboço de uma abordagem teórica. Campinas: IE/UNICAMP.

Cacciamali, Maria Cristina \& Pires, Júlio. (1996). Instituições laborais, emprego e distribuição de renda no Brasil. São Paulo em Perspectiva, 10/1, p. 27-41.

Cacciamali, Maria Cristina. (1983). Setor informal urbano e formas de participação na produção. Série Ensaios Econômicos, 26, São Paulo: IPE.

Cardoso, Adalberto Moreira. (2006). Racionalidade, contexto e trajetória: aspectos da dinâmica sindical. Paper de apoio à palestra internacional. Anais do XXVI Congresso da LASA, Porto Rico.

Cardoso, Adalberto Moreira et al. (2001). Os deserdados da indústria: reestruturação produtiva e trajetórias intersetoriais de trabalhadores demitidos na indústria brasileira. Revista Latinoamericana de Estudios del Trabajo, 7/13, p. 17-51. 
Dedecca, Claudio Salvadori. (2009). O trabalho assalariado no capitalismo brasileiro atual. In: Baltar, Paulo Eduardo; Krein, José Dari \& Salas, Carlos (orgs.). Economia e trabalho: Brasil e México. São Paulo: LTr (Debates contemporâneos 7), p. 130-150.

Dufour, Christian \& Hege, Adeilheid. (2010). Evolutions et perspectives des systèmes de négociation collective et de leurs acteurs: six cas européens: Allemagne, Espagne, France, Grande-Bretagne, Italie, Suède. Rapport de Recherche. Institut de Recherches Economiques et Sociales, Paris.

European Industrial Relations Observatory. (2010). Industrial relations developments in Europe 2009. Dublin: European Foundation for the Improvement of Living and Working Conditions. Disponível em <http://www.eurofound.europa.eu/pubdocs/2010/35/en/1/EF1035EN.pdf>. Acesso em 25 abr. 2003.

Henrique, Wilnês. (1999). O capitalismo selvagem: um estudo sobre desigualdade no Brasil. Tese de Doutorado. IE/Universidade Estadual de Campinas.

Laranjeira, Sonia Guimarães. (2003). A reestruturação das comunicações e os sindicatos. Revista Brasileira de Ciências Sociais, 18/52, jun., p. 81-107.

Medeiros, Carlos Aguiar de. (1992). Padrões de industrialização e ajuste estrutural: um estudo comparativo dos regimes salariais em capitalismos tardios. Tese de Doutorado. IE/ Universidade Estadual de Campinas.

Noronha, Eduardo Garutti. (2009). Ciclo de greves, transição política e estabilização: Brasil, 1978-2007. Lua Nova, 76, p. 119-168.

Oliveira, Francisco de. (2003). Crítica à razão dualista/O ornitorrinco. São Paulo: Boitempo.

Rodrigues, Leôncio Martins. (1999). Destino do sindicalismo. São Paulo: Edusp.

Rodrigues, Leôncio Martins. (1998). O declínio da taxa de sindicalização no Brasil: a década de 80. Revista Brasileira de Ciências Sociais, 13/36, p. 41-66.

Salm, Cláudio \& Eichenberg, Luiz. (1989). Tendencias de la integración en el mercado de trabajo brasileño. Revista de la Cepal, 39, dez., p. 65-75.

Souza, Paulo Renato. (1980). A determinação dos salários e do emprego em economias atrasadas. Tese de Doutorado. IFCH/ Universidade Estadual de Campinas. 
Palavras-chave

Sindicato; Mercado de trabalho; Desigualdade socioeconômica;

Negociação coletiva; Taxa de sindicalização.

Keywords

Union; Labor market; Socioeconomic inequality;

Collective bargain; Unionization rate.
A HETEROGENEIDADE DO MERCADO DE TRABALHO E A DESIGUALDADE NA REPRESENTAÇÃO SINDICAL

\section{Resumo}

Este artigo tem por objetivo examinar a situação recente da filiação sindical dos trabalhadores no Brasil a partir da constatação de que o quadro da sindicalização pouco se alterou nos anos 2000, apesar dos movimentos de queda do desemprego e aumento do emprego formal no mercado de trabalho. Ao procurar explicar as causas da estabilidade das taxas de sindicalização durante a última década, a análise tem como principais eixos analíticos a forte segmentação do mercado de trabalho e a desigualdade socioeconômica, notadamente no que tange ao processo incompleto de assalariamento, à heterogeneidade da condição de inserção ocupacional e à regulamentação parcial das relações de trabalho. Baseado em levantamento de dados nacional, este trabalho discute as perspectivas para a representação sindical no futuro próximo.

\section{THE HETEROGENEITY OF LABOR MARKET AND THE INEQUALITY OF UNION REPRESENTATION}

\section{Abstract}

This article aims to examine the recent situation of labor union affiliation in Brazil in order to explain the lack of dynamism of unionization in the 2000's, despite the tendency of declining unemployment and increasing occupation in the formal labor market. Regarding the causes of stability in the rates of unionization over the past decade, the article's main analytical foci are the strong segmentation of the labor market and socioeconomic inequality, especially concerning the incomplete process of employment, the heterogeneity of the condition of job placement and the partial regulation of labor relations. Based on a national data survey, this paper discusses the perspectives for union representation in the near future. 